\title{
O SIGNIFICADO DE CUIDADO PARA CRIANÇAS VÍTIMAS DE VIOLÊNCIA INTRAFAMILIAR
}

\author{
The meaning of care for children victims of domestic violence \\ El significado que tiene el cuidado para niños víctimas de
violencia familiar
}

\author{
Ruth Irmgard Bärtschi Gabatz ${ }^{1}$ \\ Eliane Tatsch Neves $^{2}$ \\ Margrid Beuter ${ }^{3}$ \\ Stela Maris de Mello Padoin ${ }^{4}$
}

\section{RESUMO}

Trata-se de uma pesquisa qualitativa que objetivou descrever o significado de cuidado vivenciado em família por crianças abrigadas que sofreram violência intrafamiliar. Foi desenvolvida em duas instituições que abrigam crianças e adolescentes vítimas de violência familiar no sul do Brasil, com quatro crianças entre 8 e 11 anos de idade. A produção dos dados ocorreu em junho/ julho de 2008 por meio do Método Criativo Sensível, com as dinâmicas de criatividade e sensibilidade Brincar em Cena e Corpo Saber. Os dados foram analisados por meio da análise de discurso francesa. Foi evidenciado como tema o significado atribuído pela criança acerca de cuidado, que se desdobrou nos subtemas Sentimento de amor e de carinho pelo familiar que cuidava e Os cuidados básicos de higiene como forma de cuidado. Recomenda-se um trabalho preventivo, realizado junto às famílias com foco em ações que propiciem o apego, o fortalecimento do vínculo mãe-filho e as relações familiares.

Palavras-chave: Violência Doméstica. Enfermagem Pediátrica. Maus-tratos Infantis. Cuidado da Criança.

\begin{abstract}
This qualitative study aimed to describe how children, victims of domestic violence, perceived the care they received in a familytype shelter. The study was developed in two institutions in southern Brazil that housed children and adolescents who suffered domestic violence. Four children, between the ages of 8 and 11, were studied in June and July of 2008. The creative and sensitive methodology (Método Criativo e Sensível), more precisely, applying the dynamics of creativity and sensitivity: Playing Act (Brincar em Cena) and Body Knowledge (Corpo Saber), was used for the production of data. The data was analyzed using the French stream of discourse analysis. The meaning that these children attributed to care was divided into two sub-themes, namely, the feeling of love and affection they felt for the family taking care of them, and how they associated the practice of basic personal hygiene as a means of concern for them. We recommend preventive work that should be carried out with the families, focusing on actions that promote closeness in order to strengthen the bond between mother and child, and the relationships within the family.
\end{abstract}

Keywords: Domestic violence. Pediatric nursing. Child abuse. Child care.

\section{Resumen}

La presente investigación cualitativa tuvo como objetivo describir el significado que tiene recibir cuidado y atención, dentro de un entorno familiar, para niños albergados que sufrieron violencia familiar. Se desarrolló con cuatro niños, entre 8 y 11 años de edad, en dos instituciones que albergan niños y adolescentes víctimas de violencia doméstica en el sur de Brasil. Los datos fueron obtenidos en junio y julio de 2008 por medio del Método Creativo Sensible (Método Criativo Sensível), más específicamente, a través de la realización de las dinámicas de creatividad y sensibilidad: "Jugar en escena" (Brincar em Cena) y "Cuerpo Saber" (Corpo Saber). Para analizar los datos se utilizó la corriente francesa de análisis del discurso. El significado que estos niños le atribuyeron al cuidado y atención se dividió en dos subtemas, el sentimiento de amor y afecto que sienten por la familia delegada para cuidarlos, y los cuidados básicos de higiene como una forma de cuidado. Recomendamos desarrollar un trabajo de tipo preventivo que debe realizarse con las familias, centrándose en acciones que promuevan el acercamiento y apego con el fin de fortalecer el vínculo madre - hijo y las relaciones dentro de la familia.

Palabras Clave: Violencia doméstica. Enfermería pediátrica. Maltrato a los niños. Cuidado del niño.

${ }^{1}$ Mestre em Enfermagem pela Universidade Federal de Santa Maria - UFSM. Professora do curso de graduação em Enfermagem da Sociedade Educacional Três de Maio - SETREM. Brasil. E-mail: rb-gabatz@uol.com.br, 2'Doutora em Enfermagem pela Escola de Enfermagem Anna Nery da Universidade Federal do Rio de Janeiro - UFRJ com estágio doutoral na McGill University com bolsa da CAPES. Professora Adjunta do Curso de Enfermagem e do Programa de Pós-graduação-Mestrado em Enfermagem da Universidade Federal de Santa Maria - UFSM - Santa Maria, RS. Brasil. E-mail: elianev@terra.com.br, ${ }^{3}$ Doutora em Enfermagem pela Escola de Enfermagem Anna Nery da Universidade Federal do Rio de Janeiro - UFRJ. Professora Adjunta do Curso de Enfermagem e do Programa de Pós-graduação-Mestrado em Enfermagem da Universidade Federal de Santa Maria - UFSM - Santa Maria, RS. Brasil. Email: beuter@terra.com.br, 4Doutora em Enfermagem pela Escola de Enfermagem Anna Nery da Universidade Federal do Rio de Janeiro - UFRJ. Professora Adjunta do Curso de Enfermagem e do Programa de Pós-graduação-Mestrado em Enfermagem da Universidade Federal de Santa Maria UFSM - Santa Maria, RS. Brasil. E-mail: padoinst@smail.ufsm.br 
Significado de cuidado para crianças vitimizadas

Gabatz RIB, Neves ET, Beuter M, Padoin SMM

\section{INTRODUCÃO}

A Organização Mundial da Saúde (OMS) define violência como o uso intencional de força ou poder físico, como ameaça ou concretamente, contra si mesmo, outra pessoa, um grupo ou comunidade, causando ou possibilitando lesões, morte, danos psicológicos ou privações. Estima-se que, no ano de 2000, aproximadamente 1,6 milhão de pessoas em todo o mundo morreram vítimas de violência, o que representa uma taxa de 28,8 por 100.000 habitantes. ${ }^{1}$

No Brasil, é possível estimar que aproximadamente 600 mil crianças e adolescentes são vítimas das diversas formas de violência doméstica, o que representa 68 por hora, ou 1 por minuto. Esses dados são apresentados como estimativa, pois ainda há uma lacuna no que se refere a uma pesquisa nacional que forneça estatísticas de violência doméstica contra crianças e adolescentes. Sabe-se também que os casos notificados de violência contra crianças e adolescentes representam uma parcela insignificante diante da realidade de ocorrências, 0 que pouco contribui para o dimensionamento epidemiológico do problema. $^{2}$

Essas ocorrências foram tratadas por muito tempo como um problema estritamente familiar, sendo sustentado como tal pela sociedade. Assim, a violência intrafamiliar foi, e continua sendo, justificada, em geral, como maneira de educar e até de demonstrar carinho e afeto. ${ }^{3}$ No entanto, esta questão não deveria ser tratada como um fato natural, considerando-se que são inúmeras as vítimas desse tipo de violência, tornando-se uma questão de saúde pública, mais do que uma questão jurídica. ${ }^{4}$

Nesse sentido, na presença da violência intrafamiliar, 0 Estado tem o dever de afastar o agressor do convívio das crianças, executando o Art. 130 do Estatuto da Criança e do Adolescente (ECA). ${ }^{5}$ Esse, a partir da hipótese de maus-tratos, opressão ou abuso sexual imposto pelos pais ou responsável, prevê que a autoridade judicial poderá determinar 0 afastamento do agressor da moradia comum, como medida cautelar.

A intervenção do Estado nas situações de violência é realizada visando o bem-estar e a proteção das crianças. Diversas leis, especialmente o ECA, foram instituídas, para possibilitar a intervenção do Estado. Entretanto, só poderão ser aplicadas quando houver quebra do silêncio que envolve a violência intrafamiliar contra criança.

Nesses casos, quando for necessário o afastamento da criança de sua família, ela será encaminhada provisoriamente a uma instituição de abrigo e, esgotadas todas as tentativas de reinserção no seio familiar, encaminhada a uma família substituta, buscando respeitar a vontade da criança.

Nesse contexto, o cuidado as crianças vítimas de violência intrafamiliar é um desafio, não só quando chegam aos serviços de saúde como também quando estão em instituições de abrigo. Exige dos profissionais conhecimentos acerca das políticas
Esc Anna Nery Rev Enferm 2010 jan-mar; 14 (1): 135-42

públicas e normas de encaminhamento de vítimas e agressores, e também o compromisso e sensibilidade. Com isso, vislumbrase evitar que a atenção se volte apenas ao tratamento das lesões, ou seja, à dimensão visível da violência (na parte física), centrada no modelo biomédico, mas a possibilidade de se desenvolver um cuidado integral.

A partir do exposto, o estudo teve como questão norteadora: Como as crianças que estão em instituições de abrigo e que foram vítimas de violência intrafamiliar vivenciaram o cuidado na família? Com esta questão elaborou-se o seguinte objetivo: descrever o significado de cuidado vivenciado na família por crianças abrigadas que sofreram violência intrafamiliar.

\section{METODOLOGIA}

Trata-se de uma pesquisa qualitativa do tipo descritivoexploratório, fundamentada no Método Criativo Sensível. ${ }^{6} 0$ protocolo de pesquisa foi aprovado pelo Comitê de Ética em Pesquisa da Universidade Federal de Santa Maria - UFSM, sob CAAE nº 0005.0.243.000-08.

Diante da situação de abrigamento das crianças, foi o seu responsável legal quem assinou o Termo de Consentimento Livre Esclarecido. Também foi utilizado o Termo de Assentimento para as crianças.

A produção dos dados ocorreu em duas instituições que acolhem crianças e adolescentes, tanto do sexo feminino quanto do masculino encaminhados pelo Juizado de Menores e Conselho Tutelar, localizadas em um município do interior do Estado do Rio Grande do Sul. Na época da produção dos dados, junho e julho de 2008, o Lar dos Meninos abrigava duas crianças, com 8 e 11 anos, e 16 adolescentes; o Lar das Meninas abrigava três crianças, com 3, 10 e 11 anos, e oito adolescentes.

Os participantes da pesquisa foram quatro crianças vítimas de violência intrafamiliar, abrigadas nesses lares, atendendo aos seguintes critérios de inclusão: ser criança e estar em idade escolar. Assim, os quatro participantes representaram a totalidade de crianças na faixa etária definida, abrigadas nos lares no momento da coleta, podendo ser essa uma limitação deste estudo. Foram atribuídos nomes fictícios aos participantes, atendendo aos preceitos éticos.

A produção dos dados ocorreu por meio das dinâmicas de criatividade e sensibilidade (DCS): 0 Brincar em Cena e Corpo Saber. A primeira (0 Brincar em cena) foi idealizada originalmente buscando conhecer a contribuição do brincar e da brincadeira na vida da criança com câncer.? Neste estudo, tal DCS foi utilizada com recursos tipo modelagem, família de bonecas da pano e desenhos, buscou-se conhecer como era a vida das crianças no ambiente da família de origem. Para instigar a ação de brincar, lançou-se a questão geradora do debate: Conte-me como é sua vida na família?

A segunda (Corpo Saber) foi adaptada para pesquisa com enfermeiras pediatras, as quais foram convidadas a fazer uma analogia entre o corpo físico humano e o corpo de conhecimento 
que possuíam sobre o uso de plantas medicinas, por meio de imagens de corpos. $^{8}$ Neste estudo, tal DCS objetivou conhecer de que forma o corpo das crianças era cuidado/tratado no ambiente da família de origem, sob a sua perspectiva. Por meio do desenho da silhueta de um corpo, buscou-se despertar a memória latente dos participantes sobre os cuidados que receberam de seus familiares. Para tanto, solicitou-se que desenhassem o seu corpo e a forma como esse era cuidado pela família. A questão geradora de debate foi: Nas atividades em casa, junto com a família de origem, como o corpo de vocês é cuidado?

Após a transcrição das DCSs, na primeira etapa da Análise de Discurso (AD) francesa, conferiu-se a materialidade

\section{RESULTADOS E DISCUSSÕES}

Após a análise dos dados emergiu o tema "o significado atribuído pela criança acerca de cuidado", que se desdobrou em dois subtemas: Sentimento de amor e de carinho pelo familiar que cuidava e Cuidados básicos de higiene como forma de cuidado. linguística ao texto, objetivando a sua compreensão o mais próximo possível da enunciação do sujeito. ${ }^{9}$ Depois disso, para organização dos dados e construção das categorias, o corpus foi organizado em quadros analíticos. Os dados transferidos aos quadros foram aqueles recortes considerados como situações existenciais dos sujeitos e que poderiam levar 0 pesquisador à compreensão de seu objeto de pesquisa.

Na segunda etapa da análise dos dados, com o intuito de compreender a linguagem utilizada pelas crianças vitimizadas, buscando maneiras de significar essa linguagem, foram aplicados ao corpus os dispositivos analíticos, incluindo a metáfora, os processos parafrásticos e a polissemia. Na terceira etapa, ocorreu a interpretação com a identificação da formação discursiva dos sujeitos. ${ }^{9}$

\section{Sentimento de amor e carinho pelo familiar que cuidava}

A partir dos discursos das crianças, identificou-se a representação dos sentimentos de amor e de carinho das crianças pelo familiar que cuidava delas. Destaca-se a situação de Gabriel, que, na dinâmica 0 Brincar em Cena, representou sua família da seguinte forma:

FIGURA 1: Desenho de Gabriel na dinâmica Brincar em Cena.

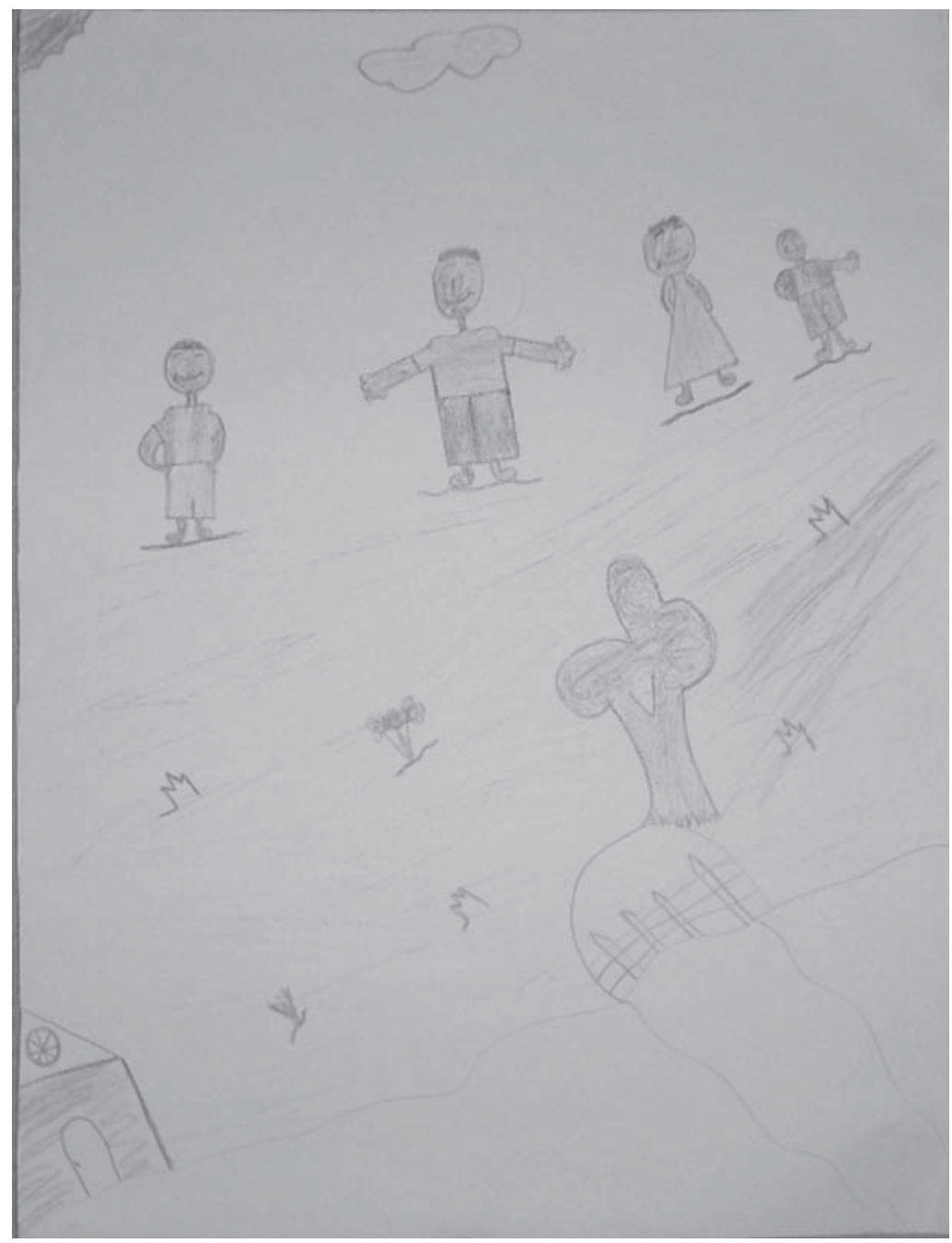


Significado de cuidado para crianças vitimizadas Gabatz RIB, Neves ET, Beuter M, Padoin SMM

Ele destacou o pai em uma posição de receptividade (braços e mãos abertos). E a mãe foi representada com as mãos escondidas. Na enunciação a seguir, Gabriel explica a sua produção.

Pesquisadora: o pai está de braços abertos por quê?

Gabriel: porque ele ia dar as mãos

Pesquisadora: para dar as mãos? Mas estão todos sem dar as mãos, por quê?

Gabriel: mas o pequeninho já tava esticando a mão para dar para mãe, que ia dar para o pai.

Pelo discurso de Gabriel, o cuidado estava presente em sua família, apontando o "dar as mãos" como forma de cuidado. Nesse sentido, o cuidado poderia ser interpretado como auxiliar, acompanhar o outro, estar junto, proteger.

Dando continuidade à DCS, Eduardo participa:

Eduardo: quem cuidava de nós era o pai. [...] eu gostava mais do pai, não gostava da minha mãe não.

Gabriel: eu também!

Eduardo: eu gostava mais do meu pai. [...] eu vim para cá porque minha mãe batia sempre em mim. [...] batia no meu pai, e ele morreu no hospital

Gabriel: e bebia. \{refere-se à mãe\}

Nesse discurso evidencia-se que os meninos gostavam mais do pai do que da mãe, pois ela batia neles. Esse foi o fato que os levou a institucionalização. 0 pai dos meninos também sofria as agressões físicas por parte da mãe. Gabriel mencionou que a mãe bebia.

A situação da mãe que agride perpassa as transformações sócio-históricas dos modelos de família e do lugar ocupado pelas crianças e pelas mulheres. ${ }^{10-11}$ Em muitas situações, está associada à história do abuso do álcool, que contribui para os conflitos interpessoais na família. ${ }^{12-13}$

Gabriel mencionou que o pai cuidava deles; observa-se que esse cuidado se relacionava, principalmente, ao fato de o pai não bater. Essa perspectiva de cuidado está pautada na proteção, as crianças manifestam o amor que sentem pelo pai, que, além de cuidar deles, as protege. 0 fato de o pai também sofrer com as agressões da mãe dos meninos fez com que eles se identificassem mais com o pai, o que pôde ser observado, diversas vezes, em seus discursos.

No discurso das crianças evidenciou-se, ainda, o amor pelo familiar que exerce o cuidado e a falta desse pelo familiar responsável pela agressão física. Fato similar é apresentado em outro estudo, em que a criança representa o sentimento de ódio pela mãe que agride. Neste mesmo estudo, o sentimento de amor pelo pai é ressaltado; em contraponto, a mãe é menos amada por ser a pessoa que mais agride a criança. ${ }^{14}$

A criança tem necessidade de se sentir amada e valorizada, sendo fundamental que os pais the deem segurança; ela "precisa ser compreendida em suas atitudes e sentimentos e se sentir apoiada" 14:228. 0 apoio, o amor e a valorização são elementos essenciais para o bem-estar das crianças, o que influenciará a maneira como irão se desenvolver emocionalmente.
Esc Anna Nery Rev Enferm 2010 jan-mar; 14 (1): 135-42

Nesse sentido, "a percepção da criança - a experiência de amor e carinho ou a falta dela - influencia e modela a maneira com que a criança se relacionará com outros"15:49.

Em seu discurso, Eduardo diz que o cuidado que recebia era prestado pelo pai e que este não batia:

Eduardo: aqui o pai lavava o pé, aqui as mãos [...] o pai não batia.

Rafaela: o pai não batia?

Eduardo: é. Não. Eaqui [...] o corpo. Ele escovava os dentes aqui, lavava os olhos [...] e esse aqui é meu pai.[ ] porque eu desenheiele.

Eduardo recodificou o seu dizer explanando sobre os cuidados que o pai tinha com ele, relacionado ao fato de o pai não bater. Nesse sentido, para Eduardo, o cuidar relaciona-se à proteção, à não agressão.

A criança vítima de violência muitas vezes tem dificuldade de se perceber como ser no mundo e expressa a percepção de si própria a partir de um familiar, em geral, aquele com o qual se identifica. ${ }^{14}$ Assim, a partir da percepção que tem do seu pai, Eduardo conseguiu identificar semelhanças com ele.

0 não cuidado foi representado nos discursos de Eduardo e Gabriel pela agressão física realizada pela mãe. Assim, o não cuidado pode estar relacionado a experiências ligadas à ameaça à vida em decorrência da violência e da agressão física. ${ }^{15}$

A partir dos discursos das crianças, o cuidado pode ser compreendido de diversas formas, como atitude de preocupação, demonstração de carinho e afeto e zelo pelo outro.

A necessidade do cuidado começa no início da vida dos seres humanos, que nascem indefesos e incapazes de sobreviver sem o cuidado de outrem. Assim, a primeira experiência de cuidado vem da própria família. É neste meio que se aprende o que é cuidado, e essa base será levada para o futuro; ou seja, sendo cuidado que se aprende e se desenvolve a capacidade de cuidar. 0 cuidado experienciado na família vem acompanhado de uma for te herança cultural, bem como de um conjunto de valores próprios de cada família.

Identificar o significado do cuidado para crianças e adolescentes possibilitará compreender como determinadas sociedades vivem, refletir sobre os valores humanos fundamentais daquela sociedade e traçar metas de ação para transformar a realidade. ${ }^{15}$

Assim, conhecer o significado do cuidado para crianças vitimizadas pela violência intrafamiliar constituiu-se um modo para compreender o seu desenvolvimento e a relação que têm ou terão com outras pessoas e com a sociedade.

\section{Cuidados básicos de higiene como forma de cuidado}

As situações descritas nesse subtema surgiram no desenvolvimento da dinâmica Corpo Saber. São aquelas situações em que os discursos das crianças evidenciaram os cuidados básicos de higiene como forma de cuidado:

Ana Júlia: [...] penteava os cabelos, lavava os olhos, escovava os dentes, lavava as mãos, cortava a unha, lavava os pés. [...] 
Rafaela:[...] lavava o cabelo, lavava os olhos, escovava os dentes, lavava a mão, vestia.

Rafaela e Ana Júlia referiram como forma de cuidado praticado por suas mães os cuidado básicos de higiene, como: lavar e pentear cabelos, lavar mãos e pés e escovar os dentes, conforme seus desenhos a seguir:

FIGURA 2: Desenho de Ana Júlia na dinâmica Corpo Saber.

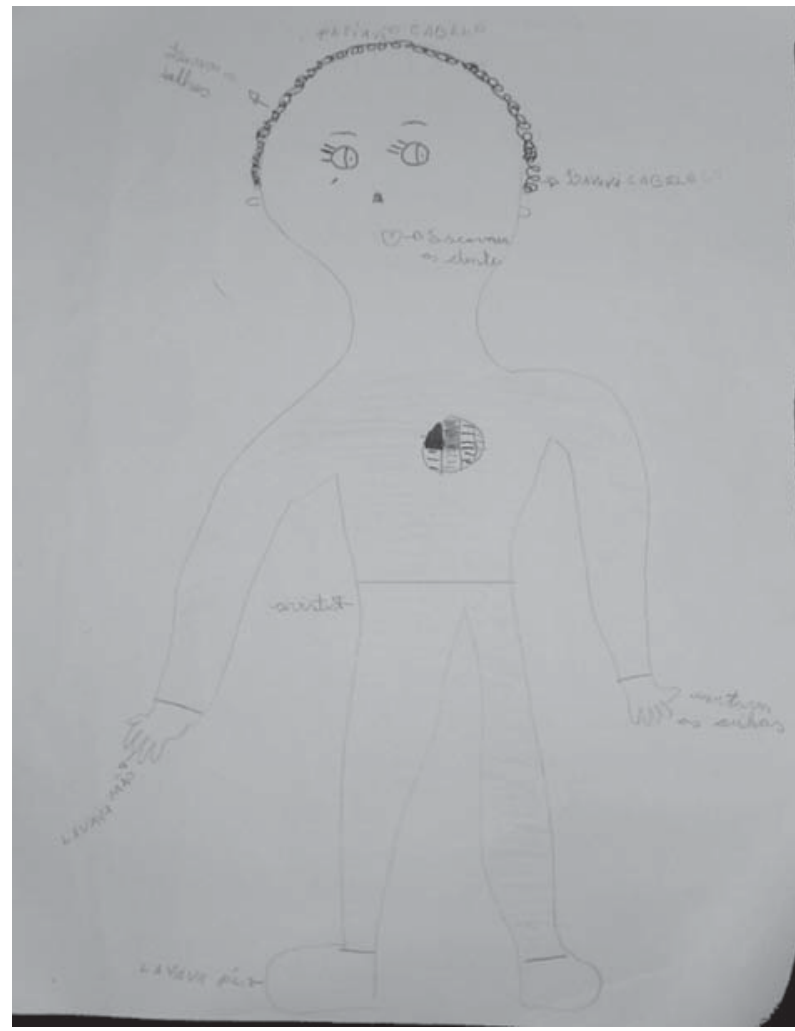

0 desenho de Ana Júlia representa uma menina que recebe os cuidados básicos de higiene. Quando indagada sobre quem realizava esses cuidados, Ana Júlia afirmou que eram realizadas pela mãe.

0 desenho de Rafaela também representa uma menina com os mesmos cuidados, sendo a mãe quem os realizava.

FIGURA 3: Desenho de Rafaela na dinâmica Corpo Saber.

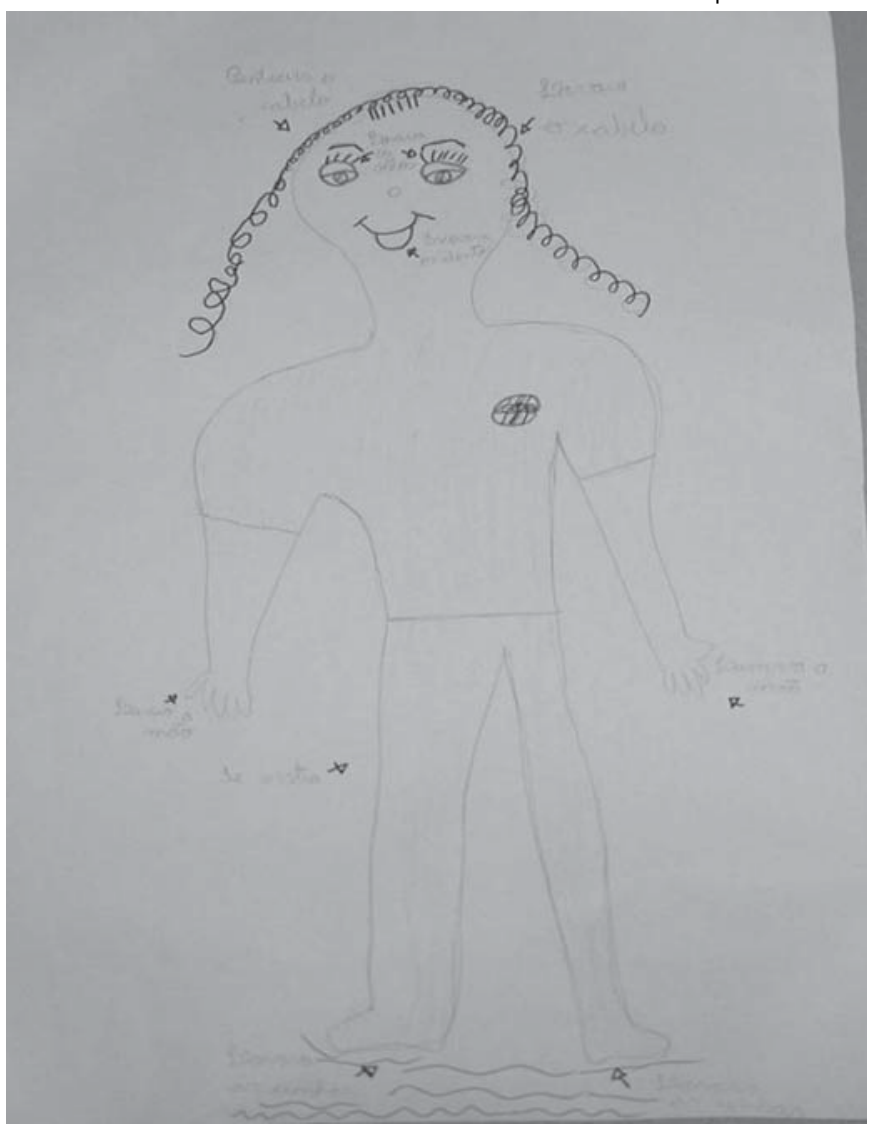


Significado de cuidado para crianças vitimizadas Gabatz RIB, Neves ET, Beuter M, Padoin SMM

Os desenhos das meninas representam o cuidado na família relacionado aos cuidados básicos de higiene. Tais cuidados, normalmente, são ensinados e/ou reforçados nas escolas e nos abrigos que recebem crianças. Têm-se esses cuidados como necessidades básicas inerentes a todas as pessoas. Observouse neste estudo que elas poderiam simplesmente estar reproduzindo o seu aprendizado escolar ou sua vivência no abrigo, e não a realidade familiar, pois, em outros momentos dos diálogos, Ana Júlia relatou nunca ter morado com a mãe e Rafaela nem lembrava de sua vida na família de origem.

0 cuidado na compreensão de crianças e adolescentes pode ser relacionado "à satisfação de um conjunto de necessidades indispensáveis à vida, que incluem alimentação, higiene, vestuário, socialização, lazer, educação e organização" 16:54. Nesse estudo, o cuidado foi descrito como cuidado básico de higiene, indo ao encontro da concepção higienista, que visa a livrar as crianças de infecções. ${ }^{16}$
No contexto de assistência prestada em creches, os cuidados relativos à higienização pessoal são explicitados como funções atribuíveis também ao enfermeiro, já que este profissional tem a possibilidade de orientar e supervisionar a higiene pessoal das crianças. Nesse contexto, cuidado também é compreendido como higiene das mãos, cabelos e pele, para prevenir a disseminação de doenças, agasalhar, hidratar, ensinar a comer. ${ }^{17}$

Desta forma, neste estudo a higiene foi apontada como um sinônimo de cuidado, por representar a preocupação com a limpeza do corpo, além de significar o cuidado em família. No decorrer da DCS Eduardo afirmou diversas vezes que era o pai que Ihe prestava os cuidados de higiene.

Eduardo: Sim. Lavava tudo, até o olho. Toda a sujeira \{referese aos cuidados que o pai lhe prestava\}.

Diferentemente dos demais, Gabriel desenhou um menino que está narrando seus cuidados, em vez de localizá-los no corpo.

FIGURA 4: Desenho de Gabriel na dinâmica Corpo Saber.

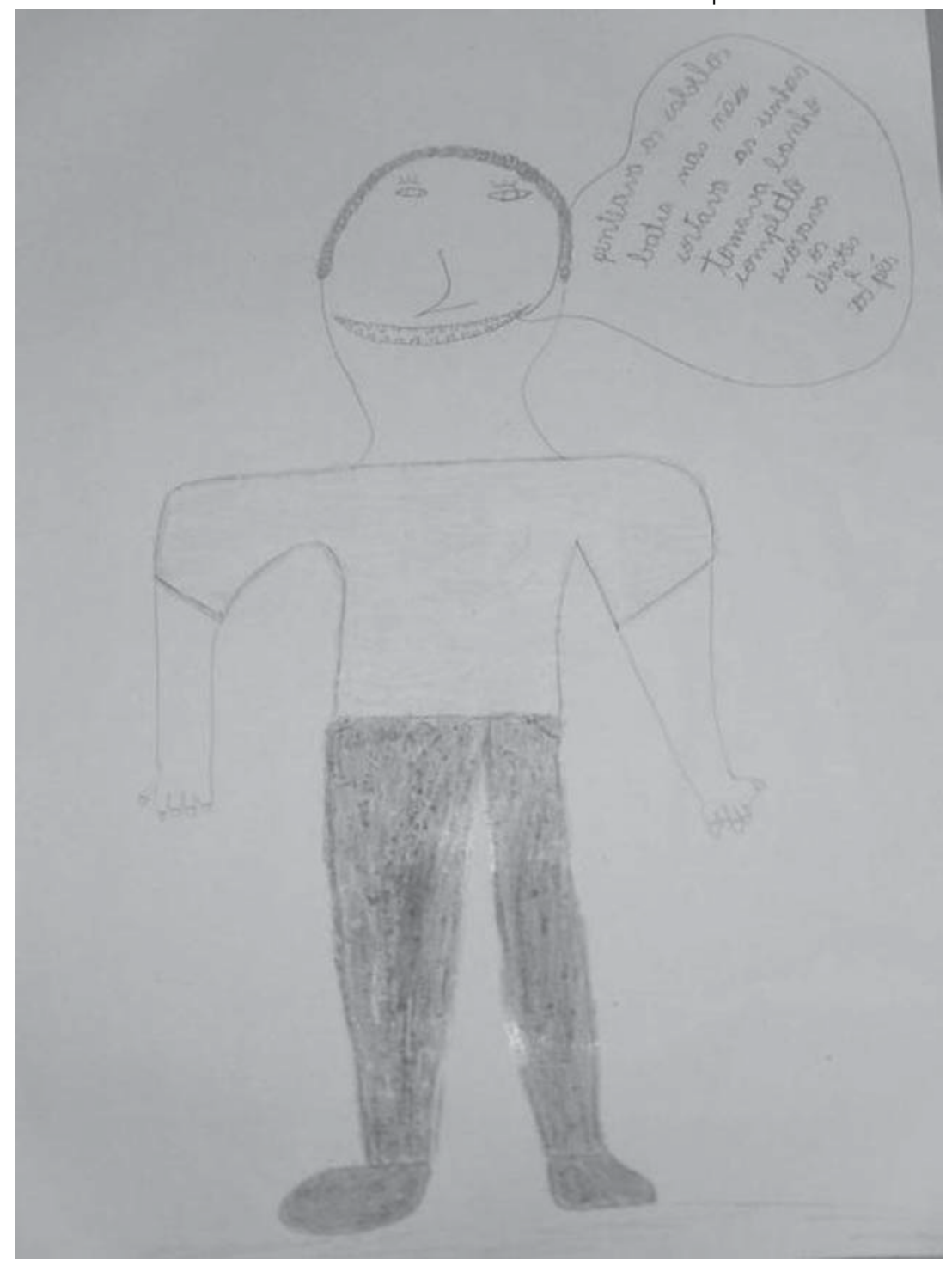


Gabriel também referiu realizar seus cuidados de higiene sozinho, descrevendo como os realizava:

Gabriel: Penteava os cabelos. [...] Oh, batia na mão. [...] Cortava as unhas, tomava banho completo. Escovava os dentes, escovava os dentes e os pés.

$\mathrm{Na}$ fase de síntese e validação das informações, procurou-se confirmar com as meninas os cuidados que acreditavam terem sido realizados pelas suas mães.

Rafaela: sim. [...] \{Rafaela afirma que sua mãe realizava seus cuidados de higiene e que a vestia\}.

Ana Júlia: a minha penteava os cabelos, escovava os dentes, lavava os olhos, lavava os cabelos, ensinou a ser do grêmio.

Rafaela e Ana Júlia reafirmaram que eram as mães que realizavam os cuidados de higiene delas; além disso, também as vestiam.

A responsabilidade com o cuidado das crianças é considerada, socialmente, como própria da esfera familiar, sendo

\section{CONSIDERAÇÕES FINAIS}

A partir deste estudo, compreende-se que, ao conhecer as vivências e o significado que as crianças dão à sua realidade vivida, torna-se possível desenvolver estratégias de cuidado convergentes com as necessidades espećificas e singulares que possuem.

0 cuidado foi abordado pelas crianças pesquisadas sob diversos enfoques, entre eles a higiene, como uma forma de cuidado na família. Rafaela e Ana Júlia representam os cuidados de higiene como forma de cuidado à saúde. Em contrapartida, Eduardo e Gabriel apresentam o cuidado relacionado à presença ou ausência da violência física.

0 cuidado referido pelas meninas encontra-se pautado nas questões de higiene, refletindo a história de violência vivenciada por elas, tendo em vista a ausência do afeto, carinho e proteção, considerados elementos essenciais do cuidado no contexto familiar.

Em contraponto, os meninos descreveram como forma de cuidado, além da realização da higiene, o fato de o pai não bater neles, demonstrando afeto por esse familiar que não agredia. A presença da violência, na agressão da mãe, está

\section{REFERÊNCIAS}

1. Organização Pan-Americana de Saúde - OPAS. Informe Mundial sobre la violência y la salud. [on-line]. Washington (DC); 2003. [citado 11 ago 2007]. Disponível em: http://www.paho.org/Spanish/AM/PUB/ violencia_2003.htm.

2. Monteiro L. Alguns dados sobre violência doméstica praticada contra crianças e adolescentes. Associação Brasileira Multiprofissional de Proteção à Infância e Adolescência-ABRAPIA 1999. [on-line] [citado 11 ago 2007]. Disponível em: http://www.abrapia.org.br/homepage/ dados_sobre_violencia_domestica.html.

3. Ribeiro EM, Eckert ER, Souza AlJ, Silva AMF. Castigo físico adotado por pais acompanhantes no disciplinamento de crianças e adolescentes. institucionalizada somente quando a família não pode cumprir seu papel. Dessa forma, essa responsabilidade continua sendo atribuída à família.

A mãe é considerada, pela sociedade em geral, como principal responsável pela saúde/doença da família e, consequentemente, pelos cuidados prestados aos seus membros. Para algumas mães, cuidar da saúde da família deve considerar a importância de uma boa alimentação e a prevenção de doenças. ${ }^{18}$

Estudos têm apontado que 0 atendimento às necessidades básicas de higiene é sinônimo de cuidado. ${ }^{16,18}$ Essa concepção é que tem permeado a realidade dos profissionais de saúde e de educação, passando pelo ideário da sociedade. Sendo assim, compreende-se que, nesse estudo, a concepção de cuidado em família, centrado nos cuidados de higiene, é aquela que perpassou no ideário das meninas.

relacionada ao não cuidado, à falta de cuidado. Assim, o cuidado representado pela ausência da violência, e o não cuidado pela presença desta, constituiu-se em um achado novo, neste estudo.

Dessa forma, conhecer a percepção que as crianças vítimas de violência intrafamiliar têm acerca do cuidado na família é importante para compreender seu desenvolvimento e a relação que têm com as outras pessoas, bem como para elaborar estratégias de atenção e cuidado mais específicas e resolutivas, pautadas na reconstrução de relaç̃̃es e nas possibilidades de preservação dos vínculos parentais e reintegração familiar.

Recomenda-se um trabalho preventivo, realizado junto às famílias, com foco em ações que propiciem o apego, o fortalecimento do vínculo da mãe com o(a) filho(a) desde o pré-natal e na puericultura, buscando identificar sinais de violência intrafamiliar, com vistas a contribuir para minimizar a ocorrência da violência intrafamiliar, como proposta de construção de uma sociedade melhor, mediada pela intervenção de profissionais de saúde e da sociedade em geral, cientes de suas responsabilidades e competências no enfrentamento dessa problemática.

Acta Paul Enferm [on-line] 2007; [citado 05 jun 2008]; 20 (3): [aprox. 7 telas]. Disponível em: http://www.scielo.br/pdf/ape/v20n3/ a06v20n3. pdf.

4. Roque EMST, Ferriani MGC. Estudo das famílias de crianças e adolescentes, vítimas de violência que sofreram intervenção da justiça. Rev Latino-am Enfermagem [on-line] 2007 jul/ago; [citado 2008 jun 05]; 15 (4): [aprox. 7 telas]. Disponível em: http://www.scielo.br/pdf /rlae/v15n4/v15n4a05. pdf.

5. Ministério da Saúde. (BR). Estatuto da Criança e do Adolescente. $3^{a}$ ed. Brasília (DF); 2006. 
Significado de cuidado para crianças vitimizadas Gabatz RIB, Neves ET, Beuter M, Padoin SMM

6. Cabral IE. 0 método criativo e sensível: alternativa de pesquisa na enfermagem. In: Gauthier JHM, organizador. Pesquisa em enfermagem: novas metodologias. Rio de Janeiro (RJ): Guanabara Koogan; 1998. p. $177-203$

7. Silva LFS, Souza NS, Cartana MHF, Cabral IE, Vernier ETN, Alvim NAT. Dinâmica da criatividade e sensibilidade "o brincar em cena": uma validação na pesquisa em enfermagem. In: Anais do $2^{\circ}$ Congresso Brasileiro de Enfermagem Pediátrica e Neonatal. $3^{\circ}$ Seminário de Saúde da Criança e Adolescente; 2007 out 4-6; Rio de Janeiro (RJ), Brasil. Rio de Janeiro(RJ): SOBEP /EEAN / NUPESC/ /UFRJ; 2007.

8. Alvim NAT. Práticas e saberes das enfermeiras sobre o uso de plantas medicinais na vida das enfermeiras: um construção em espiral [tese de doutorado]. Rio de Janeiro (RJ): Escola de Enfermagem Anna Nery/UFRJ; 1999.

9. Orlandi EP. Análise de discurso: princípios e procedimentos. $3^{\mathrm{a}}$ ed. Campinas(SP): Pontes; 2001.

10. Barbosa PZ, Pegoraro RF. Violência doméstica e psicologia hospitalar: possibilidades de atuação diante da mãe que agride. Saúde Soc. [on-line] 2008; [citado 27 jul 2009 ]; 17 (3): [aprox 13 telas]. Disponível em: http://www.scielo.br/

11. Calheiros MM, Monteiro MB. Relações familiares e práticas maternas de mau trato e de negligência. Análise psicológica. [on-line] 2007 abr; [citado 27 jul 2009]; 25 (2): [aprox. 16 telas]. Disponível em: http://www.scielo.oces.mctes.pt/pdf/
12. Reinaldo MAS, Pillon SC. Repercussões do alcoolismo nas relações familiares: estudo de caso. Rev Latino-am Enfermagem [on-line] 2008 jul/ago; [citado 27 jul 2009]; 16 (n.esp): [aprox. 6 telas]. Disponível em: http://www.scielo.br/ pdf/

13. Zanoti J, Viganó D, Laranjeira R, Figlie N. Efeitos do abuso do álcool relacionados à violência doméstica nos filhos: um levantamento bibliográfico. Rev Bras Psiq [on- line] 2008 jun; [citado 27 jul 2009]; 30 (2): [aprox. 2 telas]. Disponível em: http://www.scielo.br/ pdf/

14. Bonavides SMPB. A auto-estima da criança que sofre violência física pela família. [dissertação de mestrado]. Natal (RN): Centro de Ciências Humanas, Letras e Artes/ Programa de Pós-Graduação em Psicologia/ UFRGS; 2005.

15. Silva AL, Vogel C, Virgílio MS. Significados de cuidado para crianças e adolescentes vítimas da violência doméstica. Rev Bras Enferm 2001 jan/mar; 54 (1): 48-62.

16. Maranhão DG. 0 cuidado como elo entre saúde e educação. Cad Pesq [on-line] 2000 dez; [citado 07 out 2008] 111: [aprox. 19 telas]. Disponível em: http://www.scielo.br/ pdf/cp/n111a06.pdf .

17. Xavier TJS, Pinto FF, Souza MHN, Zeitoune RCG. Condições de saúde de crianças de creche comunitária e a enfermagem. Esc Anna Nery Rev Enferm 2003 ago; 7 (2): 204-10.

18. Martin VB, Angelo M. Significado do conceito de saúde na perspectiva de famílias em situação de risco pessoal e social. Rev Latino-am Enfermagem. [on- line] 1998 dez; [citado 07 out 2008]; 6 (5): [aprox. 7 telas]. Disponível em: http://www.scielo.br/scielo.php/ rlae/v6n5/13859. pdf . 